\title{
O DESEMPENHO DE MULTILÍNGUES EM TAREFAS DE CONTROLE INIBITÓRIO E DE PRIMING GRAFO-FÔNICO-FONOLÓGICO
}

\author{
Cintia Avila Blank ${ }^{1}$ \\ Marta Tessman Bandeira ${ }^{2}$
}

\begin{abstract}
This paper presents the results of two studies carried out among multilingual participants: one of them dealing with inhibitory control in a task called Stroop Test, and the other one involving lexical access with related grapho-phonic-phonological priming. The first test was administered to 40 participants, 20 monolingual children speakers of Brazilian Portuguese (BP), and 20 multilingual children who speak Pomeranian or German (L1), BP (L2), and English (L3). The second task was performed by three multilingual adults who speak Portuguese (L1), French (L2) and English (L3). The results of these two studies are discussed in light of the Dynamic Systems Theory.
\end{abstract}

Key-words: multilingualism, inhibitory control, memory systems, lexical access, grapho-phonic-phonological priming

\footnotetext{
1 Doutoranda do Programa de Pós-Graduaçao em Letras/Linguística Aplicada da Universidade Católica de Pelotas (UCPel/CAPES) e Professora Assistente da Universidade Federal de Pelotas (UFPel).

2 Doutoranda do Programa de Pós-Graduação em Letras/Linguística Aplicada da Universidade Católica de Pelotas (UCPel/CAPES).

Organon, Porto Alegre, n 51, julho-dezembro, 2011, p. 53-80
} 


\section{INTRODUÇÃO}

Neste trabalho, são apresentados os resultados de pesquisas feitas com duas populações de participantes multilíngues, através da aplicação de duas tarefas verbais. A primeira tarefa analisada, de controle inibitório, denomina-se Stroop Test. Ao todo, 40 crianças - subdivididas em dois grupos - realizaram a tarefa, sendo 20 monolíngues e 20 multilíngues, falantes de pomerano ou alemão como L1, português como L2 e inglês como L3. O objetivo da aplicação desse teste foi verificar se as crianças multilíngues apresentariam um desempenho significativamente melhor que as monolíngues no tempo de reação e na acurária ao realizar o teste, o que poderia ser explicado por uma vantagem no uso do controle inibitório dos multilíngues, acostumados a controlar o uso de seus vários idiomas durante suas práticas verbais cotidianas.

A segunda tarefa, de acesso lexical, envolveu priming grafo-fônicofonológico ${ }^{3}$ relacionado (não envolvendo semelhanças semânticas entre os pares testados) e foi aplicada em três participantes multilíngues adultos, falantes de português como L1, de francês como L2 e de inglês como L3. Os resultados avaliam o desempenho dos participantes em 7 das 18 combinações de tipos de pares de palavras utilizados no experimento. O objetivo da pesquisa era avaliar se haveria um aumento significativo no tempo de reação para respostas quando a L2 ou a L3 dos participantes figurasse como alvo. A hipótese que norteou a pesquisa baseou-se na suposição de que haveria um aumento significativo no tempo de reação para a combinação português-francês (P-F), já que o francês (L2) era a língua estrangeira em que os participantes possuíam um maior nível de proficiência (ao contrário do inglês), o que poderia ocasionar uma maior competição entre as correspondências grafo-fônico-fonológicas dos pares de palavras destas línguas. Esta hipótese foi lançada uma vez que os pares formados não apresentam semelhanças semânticas entre si. Com isso, presume-se que o fato de os pares apresentarem semelhanças grafêmicas e fonético-fonológicas e não compartilharem conteúdo semântico fará com que as condições

3 De acordo com Zimmer (2007), a transferência grafo-fônico-fonológica pode ser conceitualizada como uma transferência de aspectos relativos ao sistema fonético-fonológico da L1 para a L2, no momento da leitura em L2, em que o leitor, influenciado pelo sistema alfabético da L1, ativa padrões acústico-articulatórios semelhantes ou idênticos aos da L1, ao invés dos da L2. 
interlinguísticas analisadas, principalmente as envolvendo português como prime e francês como alvo, evidenciem tempos de reação significativamente maiores do que os pares envolvendo português como prime e inglês como alvo (DE BOT, 2004, DIJKSTRA et al., 2002, VAN WIJNENDALE, 2002).

Para apresentar os resultados obtidos nesta pesquisa, este artigo divide-se em quatro seções, que tratam, respectivamente, de aprofundar os pressupostos teóricos envolvidos na discussão do tema; apresentar a metodologia aplicada; discutir os resultados obtidos; apresentar as conclusões mais significativas para a pesquisa.

\section{Considerações por uma visão dinâmica de bi/multilinguismo}

A pesquisa em multilinguismo ainda é bastante recente no cenário acadêmico. Muitas vezes explicada como apenas uma simples variação do que se entende por aquisição de L2, a aquisição de três ou mais línguas ainda carece de estudos, a despeito do grande interesse que parece surgir a respeito deste tema.

Cenoz (2000), conhecida por suas pesquisas em multilinguismo, alerta para o erro em se considerar a aquisição multilíngue da mesma forma como a aquisição de uma L2, defendendo que o multilinguismo deve ser entendido como a aquisição de outras línguas que não a L1 e a primeira língua estrangeira ${ }^{4}$ (L2) do indivíduo. Nesse sentido, o multilinguismo ganha seu próprio espaço e passa a ser analisado a partir de uma nova perspectiva, que leva em conta o fato de ser este tipo de aquisição um processo mais complexo do que a aquisição de uma segunda língua. Como argumentos para corroborar essa visão, pode-se chamar a atenção para o fato de que, além de implicar todos os fatores e processos associados à aquisição de L2, o multilinguismo apresenta fatores unicamente e potencialmente mais complexos, além de efeitos associados às interações que podem ocorrer entre as múltiplas línguas sendo aprendidas e usadas ao mesmo tempo.

Dentro de uma tendência mais integradora, os estudos em multilinguismo procuram defender a ideia de que o bilinguismo exerceria

4 Não é feita aqui a distinção entre aquisição e aprendizagem, propugnada por Krashen (1986), nem entre os termos "língua estrangeira" e "L2", já que o referencial teórico aqui adotado não parte de dicotomias estanques como competência e desempenho, típicas do cognitivismo de cunho simbólico. Portanto, os termos língua-alvo, L2, segunda língua e língua estrangeira serão usados intercambiavelmente ao longo deste trabalho.

Organon, Porto Alegre, nº 51, julho-dezembro, 2011, p. 53-80 
uma influência positiva sobre a aprendizagem de uma terceira língua, conforme apontam estudos de Cenoz e Valencia (1994), Thomas (1988) e Lasagabaster (1997). Existe muito mais diversidade e complexidade envolvida no processo de aquisição multilíngue quando comparada à aquisição bilíngue se forem considerados fatores como a idade em que as diferentes línguas estrangeiras foram aprendidas, o ambiente em que cada uma das línguas foi aprendida e até mesmo a distância tipológica entre as línguas envolvidas (CENOZ, 2000). Assim, parte-se do princípio de que a transferência entre línguas originada do contato entre elas pode ser significativamente positiva, e não apenas negativa, como frequentemente é defendida. Além disso, os estudos sobre multilinguismo têm defendido a integração entre as línguas do multilíngue no sistema cognitivo (DE BOT, 2004; CENOZ, 2000; WEI, 2008). No Brasil, as pesquisas em multilinguismo já nascem apoiando e fortificando essa visão, além de defenderem um importante benefício cognitivo advindo do fato de se falar várias línguas, que reside na possibilidade de o bi/multilinguismo apresentar um efeito protetor contra o declínio de funções cognitivas que acometem idosos, por exemplo (PINTO; ZIMMER, 2010; ZIMMER; FINGER, este volume).

Ainda defendendo uma visão mais integradora de bi/multilinguismo, cabe referir a utilização da Teoria dos Sistemas Dinâmicos para o estudo da aquisição de línguas. Nessa perspectiva, Elman (1995) prefere entender a linguagem como um sistema dinâmico, e não como um sistema representacional, uma vez que o cérebro, órgão por meio do qual processamos e expressamos a linguagem, é dotado de plasticidade, o que permite que seja modelado de acordo com o meio ao qual estiver exposto. Port (2002) usa a metáfora da tecelagem para descrever o sistema dinâmico, apontando que este parece um tear: em alguns momentos há uma interação complexa de muitos grupos neurais. As atividades em cada grupo são integradas. Da mesma forma, o pensamento se dá como um tear - um produto de todo um sistema de atividades.

Dentro do mesmo enfoque, De Bot et al. (2007) veem a linguagem como um sistema dinâmico, ou seja, como um conjunto de variáveis que interagem no tempo. Assim, o desenvolvimento da linguagem passa a ser visto como um processo dinâmico, à medida que apresenta as principais características presentes nesse tipo de sistema: dependência sensível do estado inicial de desenvolvimento, interconectividade dos 
subsistemas, emergência de atratores no tempo e variação entre indivíduos. Dessa forma, chama-se a atenção para a necessidade premente de encarar os estudos em multilinguismo a partir de um enfoque integrador, sem que se recorra a separações e divisões entre línguas. Afinal, padrões de comportamento linguístico são construídos e modificados dentro do mesmo sistema cognitivo a partir de múltiplas interações sujeito-input ambiental/sujeito(s) e desenvolvem-se, dessa forma, dentro de um sistema maior, a cognição situada ${ }^{5}$ de um indivíduo.

Trazendo o foco para a questão do multilinguismo e do acesso lexical em multilíngues, cabe fazer referência ao modelo de aquisição multilíngue desenvolvido por De Bot (2004). Em sua teoria denominada Modelo de Processamento Multilíngue (The Multilingual Processing Model), De Bot faz considerações que se mostram relevantes para esta pesquisa. No que compete à questão do acesso lexical, o autor defende que as línguas aprendidas pelo trilíngue sempre são ativadas simultaneamente, o que acaba gerando uma competição constante entre elas tanto no momento da produção quanto da percepção linguística. Entretanto, isso não implica que todas as palavras de todas as línguas do trilíngue tenham as mesmas chances de serem ativadas. Para De Bot (op. cit.), as línguas que forem ativadas com mais frequência, ou seja, aquelas que apresentarem um maior nível de proficiência tenderão a sobrepujar as demais.

Na próxima seção, serão esclarecidos alguns pontos-chave sobre o entendimento das funções executivas e do controle inibitório, para que se conheça o embasamento utilizado para a criação da hipótese formulada para a aplicação da tarefa Stroop em monolíngues e multilíngues.

\section{Funções executivas e controle inibitório}

As funções executivas estão entre os aspectos mais complexos da cognição e envolvem seleção de informações, integração de informações atuais com informações previamente memorizadas, planejamento, monitoramento e flexibilidade cognitiva (GAZZANIGA et al., 2002; LEZAK,

5 A noção de cognição corporificada, que encontra forte eco na Linguística Cognitiva, com a relevância da base corpórea presente nas metáforas que embasam o pensamento humano (LAKOFF e JONHSON, 1997), está presente há bastante tempo na visão cognitiva dinâmica. É evidente, portanto, a valorização do sistema biológico, do movimento e do tempo real através da proposição de um continuum entre o corpo, a cognição motora, o cérebro e a cognição mental, o que corporifica e situa a cognição (PORT, 2002).

Organon, Porto Alegre, nº 51, julho-dezembro, 2011, p. 53-80 
1995). Na ótica da avaliação neuropsicológica, o termo função executiva é usado para nomear uma ampla variedade de funções cognitivas que pressupõem atenção, concentração, seletividade de estímulos, capacidade de abstração, planejamento, flexibilidade, controle mental, autocontrole e memória operacional (HAMDAN; BUENO, 2005).

A localização anatômica do processamento cognitivo das FEs é no córtex pré-frontal. Cappovila et al. (2007) afirmam que o córtex préfrontal, que ocupa quase um terço da massa total do córtex, mantém relações múltiplas e quase sempre recíprocas com inúmeras outras estruturas encefálicas. Tais relações correspondem a conexões com regiões de associação do córtex parietal, temporal e occipital, bem como com diversas estruturas subcorticais, especialmente com o tálamo, e possui as únicas representações corticais de informações provenientes do sistema límbico. Acontecem no córtex pré-frontal processos cognitivos que abarcam o desempenho de subcomponentes, dentre os quais se destacam: focalização da atenção em informações relevantes, inibição de processos e informações concorrentes, programação de processos para tarefas complexas que necessitam de alternâncias entre elas (KRISTENSEN, 2006).

As funções executivas são o produto de uma operação realizada por vários processos cognitivos, a fim de executar uma tarefa específica, e o controle executivo (CE) pode ser entendido como o mecanismo responsável pela coordenação de vários processos implicados na realização das FEs.

O controle inibitório, por sua vez, é um componente-chave das Funções Executivas, pois lida com o controle do pensamento e da ação. Outros componentes das Funções Executivas são resistência à interferência, memória de trabalho (habilidade de manipular informações da memória de curto prazo) e a habilidade de planejamento. Como o próprio nome diz, o controle inibitório inibe a atenção aos estímulos menos importantes. A falta deste controle torna a pessoa mais confiante com o que é mais exercitado, familiar e parte da rotina - o que caracteriza respostas automáticas - e menos capaz de ter pensamentos originais. Além disso, sem a adequada inibição, a memória de trabalho se ocupa com informações irrelevantes e há a diminuição da eficiência do processamento cognitivo.

Segundo Bialystok (2001), uma vantagem exibida pelas crianças bilíngues está relacionada a um melhor funcionamento de funções exe-

Organon, Porto Alegre, no 51 , julho-dezembro, 2011, p. 53-80 
cutivas, como a atenção e o controle inibitório. As crianças bilíngues são capazes de inibir a atenção para informações dispersivas de grande saliência e complexidade, muito mais do que as monolíngues. Green (1998) propôs um modelo baseado no controle inibitório, no qual a língua não relevante é eliminada pelas funções do sistema executivo usado normalmente para controlar a atenção e a inibição.

Na próxima seção, apresenta-se conceito de priming, fundamental para a compreensão da tarefa de acesso lexical feita por um dos grupos de multilíngues.

\section{Conceitualizando o priming}

O conceito de priming pode ser descrito como a ativação de partes de representações particulares ou de associações na memória antes de se desempenhar uma ação ou tarefa (Busnello, 2007). Os experimentos de priming procuram investigar eventos relacionados à percepção préconsciente e à memória implícita, o que está ligado ao processamento involuntário. A percepção de algum estímulo, nesse caso, é automática e ocorre de forma inconsciente. Durante a realização de tarefas desse tipo, estímulos são utilizados para sensibilizar o sujeito a uma apresentação posterior desse mesmo estímulo ou de um estímulo semelhante ao apresentado. Esses estímulos podem ser veiculados através de imagens, palavras, sons ou objetos.

De acordo com Anderson (2004), o efeito de priming pode ser explicado partindo-se da idéia de que o conhecimento armazena-se na memória em "nós" associativos, os quais compõem redes de informações interconectadas. Dessa forma, quando um nó é ativado, essa ativação vai aumentando e distribuindo-se, até que o estímulo seja propagado na rede, ativando memórias associadas.

Vários tipos de experimentos podem ser realizados dentro dos estudos sobre o priming. Os designs dos experimentos variam, assim, de acordo com os propósitos investigados. Dessa forma, podem-se criar experimentos nos quais prime e o alvo são apresentados com ou sem contexto semântico; com ou sem semelhanças grafêmicas; com ou sem semelhanças fonológicas. Dessa forma, prime e alvo podem vir a ser idênticos, semelhantes ou completamente diferentes no que diz respeito às características linguísticas citadas acima. Neste estudo, trabalha-se com a manipulação de pares de palavras que apresentam semelhanças

Organon, Porto Alegre, n 51, julho-dezembro, 2011, p. 53-80 
ortográficas e fonético-fonológicas, porém, o conteúdo semântico dos pares montados não apresenta nenhum tipo de semelhança.

A hipótese traçada para o experimento de priming (português como prime e francês como alvo demandarão maior tempo de reação para respostas do que português como prime e inglês como alvo) baseia-se na ideia de que existe um mecanismo de busca em paralelo para todas as línguas do multilíngue, em que palavras não são organizadas por língua, mas sim por frequência (DE BOT, 2004). No caso aqui estudado, parte-se do pressuposto que os participantes possuem maior frequência de exposição aos itens lexicais em francês, língua mais proficiente.

Além do papel da frequência para a ativação lexical, deve-se destacar também os efeitos de vizinhança que podem surgir quando são utilizadas palavras muito semelhantes graficamente, ainda mais em línguas diferentes, já que a ativação fonético-fonológica costuma ser bastante divergente entre as línguas. De acordo com De Bot (2004), palavras que apresentam várias vizinhas, ou seja, palavras que possuem similaridades com outras que se distinguem em apenas uma letra ou um som, costumam requerer mais tempo para leitura do que palavras que apresentam poucos vizinhos (Neighbourhood Effects). De Bot (2004) define que uma palavra com muitas vizinhas possui muitos candidatos competindo junto para o seu acesso. Isso, de acordo com o autor, dificulta a seleção da palavra adequada, aumentando o tempo necessário para que a palavra-alvo seja acessada.

Evidências de um funcionamento em paralelo para o léxico são levantadas para monolíngues por Dijkstra e Van Heuven (2002) e para bilíngues por Jared e Kroll (2001). Para multilíngues, Blank (2008) realizou teste de leitura de palavras em duas línguas (inglês e francês), replicada de Jared e Kroll (2001), contendo palavras da língua inglesa que apresentavam 3 tipos: palavras com corpos grafêmicos consistentes na própria língua (palavras não-inimigas), inconsistentes na própria língua (palavras inimigas do inglês) e inconsistentes em relação a palavras da língua francesa que evidenciassem os mesmos tipos de corpos de palavras (palavras inimigas do francês). As palavras da língua francesa veiculadas no teste de leitura apresentavam corpos grafêmicos semelhantes aos de um dos tipos de palavras lidas em língua inglesa (palavras inimigas do francês). O resultado do teste de leitura evidenciou um aumento significativo no tempo de reação para as palavras do 
inglês cujos corpos grafêmicos eram semelhantes em inglês e francês, trazendo evidências para que se pense num funcionamento lexical não seletivo e em paralelo. Esses achados estão de acordo com os resultados que Jared e Kroll (2001) encontraram para os bilíngues que realizaram a mesma tarefa mencionada.

Embora o paradigma de priming, de modo geral, preconize um efeito facilitador para o reconhecimento de um alvo em função da pré-ativação de um priming, os resultados das tarefas realizadas nem sempre trazem evidências nessa direção, como pôde-se observar nos resultados ora relatados, indicando uma necessidade para que se leve em conta os diferentes tipos de manipulação que podem ser executados nos itens a serem testados.

No que tange às tarefas de priming lexical, Van Wijnendaele e Brysbaert (2002), por exemplo, chamam a atenção para alguns fatores determinantes para que se tenha um efeito de facilitação ou não do prime sobre o alvo, sobretudo em tarefas interlinguísticas. Assim, fatores como a proficiência dos participantes em suas línguas, a frequência dos itens lexicais utilizados no teste e a correspondência entre grafemas e fonemas nas línguas testadas influenciam de forma expressiva os resultados que podem ser obtidos. Segundo os autores, palavras de baixa frequência apresentadas como alvo são dificilmente reconhecidas quando palavras de alta frequência são apresentadas como priming. Além disso, a proficiência equilibrada entre as línguas também pode dificultar o acesso ao alvo quando palavras de grafia semelhante, mas com diferentes ativações fonológicas, são apresentadas. Para Wijnendaele e Brysbaert (2002), bilíngues altamente proficientes em francês e inglês teriam mais problemas para processar a palavra francesa "AMONT" se esta fosse precedida pelo prime "among", do que se fosse precedida pela palavra controle "drive".

Tendo em conta os resultados ora apresentados, o presente estudo assume a abordagem não-seletiva para o funcionamento lexical. Ainda, ao utlizar-se de palavras homógrafas e homófonas no experimento de priming utilizado aqui, adota-se a visão de De Bot (2004) e Dijkstra e Van Heuven (2002) de que a apresentação de palavras desses tipos em várias línguas pode gerar competição e aumento no tempo de reação para respostas. Na próxima seção, será exposta a relação entre o modelo HipCort e o processo de priming neste estudo.

Organon, Porto Alegre, nº 51, julho-dezembro, 2011, p. 53-80 


\section{O Modelo HipCort}

O modelo HipCort (McClelland et al., 1995) admite que os dois sistemas de memória, hipocampal e neocortical, interagem, sendo ambos responsáveis pela formação da memória e da aprendizagem. De acordo com os autores, quando indivíduos são expostos a uma dada experiência, esta é representada, no sistema neocortical, por padrões amplamente distribuídos na atividade neural. Mesmo se considerando que a referida experiência leve a pequenas mudanças adaptativas nos pesos das conexões neuronais, é defendido que tais mudanças não seriam suficientes para ensejar o desempenho de uma série de tarefas, tais como a aprendizagem rápida e a atividade de associações arbitrárias, já que, para tais processamentos, é necessário o envolvimento do sistema hipocampal. Por isso, o modelo HipCort admite que a aprendizagem e a memória são formadas a partir de mudanças substanciais nos pesos das conexões entre os neurônios no sistema hipocampal, que é extremamente rápido e possui um mecanismo de aprendizagem praticamente instantâneo. Assim, as informações são levadas tanto no sentido do sistema hipocampal para o neocortical, como também do neocortical para o hipocampal, através de caminhos bidirecionais que traduzem os padrões de atividade de um sistema para o outro.

Em suma, a aprendizagem parece ter um mecanismo de consolidação extremamente lento e gradual. Para que uma experiência qualquer seja aprendida e uma memória criada, é preciso que essa experiência seja apresentada ao sistema hipocampal repetidas vezes, proporcionando pequenos reajustes nos pesos das conexões. Dessa forma, um traço de memória será gerado, podendo ser reativado de maneira explícita pelo reinstanciamento das sinapses hipocampais no neocórtex.

Através da forma como os dois sistemas de memória interagem, é possível explicar o fenômeno da transferência linguística, que ocorre quando o conhecimento prévio do aprendiz, incluída aí sua língua materna, difere, em diferentes graus, dos novos padrões - fonético-fonológicos, sintáticos, semânticos - referentes à língua que está sendo aprendida. Assim, esses novos padrões competem com os padrões da língua materna no sistema neocortical, em função de os pareamentos entre escrita e som ou forma e significado relativos à L1 estarem há mais tempo consolidados no sistema cognitivo do aprendiz.

É importante ressaltar a importância de utilizar-se o Modelo HipCort para amparar a hipótese lançada aqui para a tarefa de priming. 
Já que o modelo prevê a interação entre os conhecimentos implícitos (mais relacionados ao neocórtex) e explícitos (mais relacionados ao hipocampo), pode-se pensar que haverá uma maior competição lexical entre os pares que exibirem primes em português e alvos em francês, já que essas são as línguas que podem estar mais consolidadas nos sistemas de memória dos participantes (mais relacionadas ao sistema neocortical, porém, em graus diferentes). Assim, poderá haver uma maior dificuldade por parte dos participantes para inibir a ativação dos primes em português quando os alvos forem apresentados em francês, já que a alta proficiência nesta língua poderá gerar um grau de transferência significativo. Já quando os alvos forem apresentados em inglês, é possível que os participantes reajam mais rápido ao responder, visto que a baixa proficiência em língua inglesa pode não ser capaz de competir de forma significativa com a ativação prévia da língua materna, mais consolidada nos sistemas de memória. Ressaltando, mais uma vez, que não há semelhanças semânticas entre os pares testados na tarefa de priming aqui utilizada.

Na próxima seção, serão apresentados os participantes e os objetivos da pesquisa e será descrito o método experimental utilizado nas duas tarefas relatadas neste estudo.

\section{MÉTODO}

Nesta seção, pretende-se descrever o perfil dos participantes desta pesquisa, bem como apresentar os experimentos aplicados nas duas pesquisas aqui relacionadas. As pesquisas a serem apresentadas têm como foco central avaliar o desempenho de participantes multilíngues realizando tarefas lingüísticas online.

A tarefa denominada Stroop Test foi aplicada com o objetivo de avaliar se haveria uma diferença significativa entre o desempenho de crianças monolíngues e multilíngues ao realizar a tarefa de controle inibitório e se as crianças multilíngues apresentariam um maior controle inibitório que as monolíngues ao realizar o teste. A hipótese defendida é a de que as crianças multilíngues sair-se-iam melhor nesta tarefa, já que o fato de estarem acostumadas a controlar o uso de seus vários idiomas durante suas práticas verbais cotidianas poderia auxiliar no momento de terem de controlar as respostas para a decisão de nomes

Organon, Porto Alegre, n 51, julho-dezembro, 2011, p. 53-80 
de cores vs. cores em que os referidos nomes de cores eram grafados. Tratam-se, portanto, de processamentos cognitivos da mesma natureza, que se julgam estarem correlacionados.

A tarefa de priming grafo-fônico-fonológico relacionado foi aplicada com o objetivo de avaliar se haveria um aumento significativo no tempo de reação para respostas quando palavras na L2 (francês) ou na L3 (inglês) dos participantes fossem apresentadas na posição de alvo, ou seja, logo após os primes na L1 (português) dos participantes. Como hipótese, estabeleceu-se que poderia haver um aumento significativo no tempo de reação para a combinação que apresentava a L2 como alvo (P-F), já que o francês (L2) era a língua estrangeira em que os participantes possuíam um maior nível de proficiência. Essa hipótese está amparada pelos estudos de De Bot (2004) e Dijkstra e Van Heuven (2002), os quais defendem um funcionamento não-seletivo para o léxico, apresentando evidências para um funcionamento lexical em paralelo. Além disso, os referidos autores defendem que palavras homógrafas e homófonas quando testadas em várias línguas podem apresentar tempos de reação maiores para respostas, já que há uma competição entre as ativações das referidas palavras, além da falta de conteúdo semântico similar, o que pode dificultar ainda mais o acesso rápido à palavra adequada.

Na próxima seção, os participantes da pesquisa terão seus perfis descritos.

\section{Participantes}

Participantes do teste de Stroop

Participaram desta parte da pesquisa 40 crianças, sendo 20 monolíngues e 20 multilíngues, com idade média entre 8 e 10 anos. As crianças são residentes na cidade de Arroio do Padre, Rio Grande do Sul, e cursavam a $3^{\text {a }}$ série do ensino fundamental na ocasião da coleta dos dados. Cabe explicar que a cidade de Arroio do Padre carateriza-se por sua forte colonização pomerana e alemã, o que deixou heranças linguísticas na cidade até hoje, já que a maioria da população fala, ou pelo menos compreende os referidos idiomas. Trata-se também de uma cidade de acesso relativamente limitado, o que também contribui para o uso cotidiano do pomerano e ou do alemão como L1, favorecendo a ocorrência do multilinguismo nesse contexto. As crianças multilíngues são falantes do pomerano e/ou alemão desde o nascimento (bilinguismo societal) e 
têm a oportunidade de realmente usar o português brasileiro somente por volta dos 6 anos, quando começam a estudar na escola.

Participantes da tarefa de priming

Participaram desta parte da pesquisa 3 sujeitos, 2 mulheres e um homem, apresentando idade média de 23,3 anos de idade. Os três participantes formaram-se no curso de Licenciatura em Letras da Universidade Federal de Pelotas (UFPel), tendo colado grau na dupla habilitação Português-Francês. Um dos participantes, após formar-se, retornou à faculdade na condição de aluno do curso de Letras-Inglês e encontrava-se no segundo semestre do curso no momento da testagem. Os demais participantes haviam começado um curso de extensão em língua inglesa também na UFPel e finalizavam o módulo 2 (o que equivale a 2 semestres de curso). Mesmo assim, todos os participantes submeteram-se à realização de provas de proficiência nas suas línguas estrangeiras (francês e inglês), tendo sido classificados com proficiência alta em francês e intermediária em inglês. Os testes de proficiência realizados foram o DALF, para a língua francesa, e o TOEIC, para a língua inglesa. Além disso, os 3 participantes assinaram um termo de consentimento para que pudessem participar da pesquisa. Cabe referir, por fim, alguns critérios que foram seguidos para a escolha dos participantes. Em primeiro lugar, todos deveriam ser falantes nativos do português brasileiro e, para finalizar, não poderiam ter conhecimento de outros idiomas além dos aqui investigados.

A seguir, os experimentos utilizados nas pesquisas serão apresentados.

\section{Experimentos}

Experimento Stroop Test

Os dois grupos - crianças monolíngues e crianças multilíngues responderam, em sessões individuais, ao Teste Stroop. Esse teste tem por objetivo avaliar o controle inibitório do participante através de uma tarefa na qual era apresentado ao participante estímulos com nomes de cores (vermelho, verde, azul e rosa) que apareciam no centro da tela de um computador, a partir do qual os participantes deveriam pressionar as teclas 1 e 0 do teclado, conforme os nomes das cores apareciam na tela para dar suas respostas.

Organon, Porto Alegre, n 51, julho-dezembro, 2011, p. 53-80 
Por exemplo, se estivesse escrito em letras azuis a palavra "vermelho", havia duas opções de resposta: 1 para azul e 0 para vermelho. Nesse caso, a resposta correta seria azul; portanto, a tecla 1 deveria ser pressionada. Essa condição é denominada incongruente, pois o estimulo da cor não corresponde ao nome da palavra escrita. Também foram apresentados nomes de cores com a correspondente tinta, por exemplo, "vermelho" escrito com tinta vermelha. Essa condição da tarefa é considerada como congruente, porque não há competição entre o estímulo visual (a cor em que a palavra está escrita) e o estímulo lexical (o nome da cor). Esses dois tipos de estímulos foram apresentados aleatoriamente. Esse mesmo teste foi realizado em pomerano (L1) e em português (L2).

O efeito Stroop é demonstrado pela subtração do tempo de reação da tarefa na condição incongruente da congruente e em separado da acurácia. Esta diferença demonstra o tempo de reação que o sujeito leva para reconhecer a cor em que a palavra está escrita na condição incongruente, o que gera o efeito Stroop.

Se um dado estímulo pode evocar ações diferentes por parte do falante, tarefas diferenciadas estão potencialmente em competição para controlar o output. Em certos casos, alguns esquemas de tarefas irrelevantes parecem ser automaticamente elucidadas pelo estímulo. Então, quando indivíduos são solicitados a nomear a cor com a qual um símbolo é escrito, quanto mais parecido for o símbolo com a palavra, menor será a interferência com a nomeação das cores, sugerindo que um esquema de leitura pode ser elucidado por inputs similares àqueles normalmente desencadeados, conforme se observa na figura 1 .

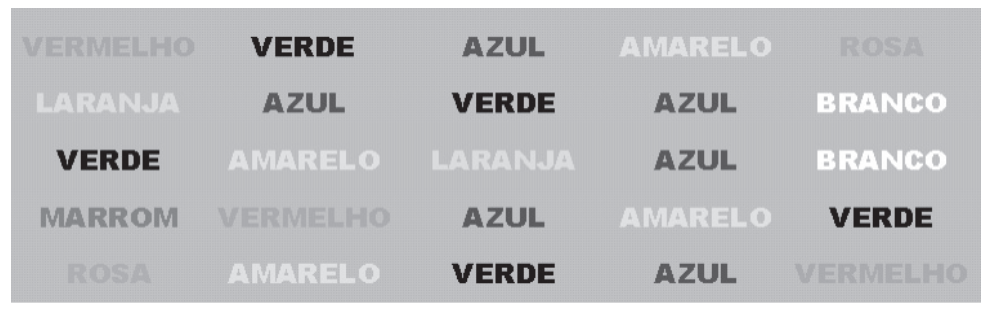

Fig. 1 - Teste de Stroop no qual as cores representam fielmente as palavras correspondentes.

Contudo, parte da base da interferência de Stroop pode se originar da competição entre esquemas de tarefas. Mais interferência pode

Organon, Porto Alegre, no 51 , julho-dezembro, 2011, p. 53-80 
ser causada se a cor da letra não coincidir com o nome da cor escrita (Stroop, 1935), criando uma competição gerada pela incongruência entre os estímulos visual (cor) e gráfico (nome da cor), conforme pode ser observado na figura 2.

$\begin{array}{ccccc}\text { VERMELHO } & \text { VERDE } & \text { AZUL } & \text { AMARELO } & \text { ROSA } \\ \text { LARANJA } & \text { AZUL } & \text { VERDE } & \text { AZUL } & \text { BRANCO } \\ \text { VERDE } & \text { AMARELO } & \text { LARANJA } & \text { AZUL } & \text { BRANCO } \\ \text { MARROM } & \text { VERMIELHO } & \text { AZUL } & \text { AMARELO } & \text { VERDE } \\ \text { ROSA } & \text { AMARELO } & \text { VERDE } & \text { AZUL } & \text { VERMELHO }\end{array}$

Fig. 2 - Teste de Stroop na versão incongruente, isto é, na versão em que as cores não correspondem a sua representação gráfica.

Foi feito um teste piloto com apenas oito participantes, todos falantes de pomerano como L1 e com as palavras escritas em português (L2), no qual se constatou que o teste foi feito com relativa dificuldade, pois os próprios participantes observaram que teriam um desempenho muito melhor se fosse feito na sua língua mãe - o pomerano. O pomerano, língua de imigração, é falado somente em alguns lugares do Brasil, como já mencionado anteriormente, e é uma língua ágrafa. Assim, para a realização desse teste em pomerano, foi solicitado aos participantes que escrevessem, da maneira que melhor lhes parecesse, a grafia das palavras que nomeavam as cores em pomerano. As palavras foram grafadas de forma semelhante ao alemão padrão, uma vez que o nome das cores coincide em alemão e em pomerano, e foi elaborada também uma versão em pomerano do teste Stroop.

$\mathrm{Na}$ próxima seção, o segundo experimento a ser analisado neste artigo será mais bem detalhado.

\section{Experimento de priming}

$\mathrm{O}$ segundo experimento utilizado nesta pesquisa caracteriza-se por ser uma tarefa de acesso lexical contendo priming grafo-fônicofonológico relacionado. Esta tarefa, em sua íntegra, foi construída com um total de 108 pares de palavras - 54 apresentando semelhanças de ordem ortográfica ou fonético-fonológica, mostrando prime e alvo reOrganon, Porto Alegre, n 51, julho-dezembro, 2011, p. 53-80 
lacionados; e 54 sem nenhum tipo de semelhança. Esses pares foram distribuídos entre 18 possibilidades de apresentação, de acordo com a combinação entre as línguas e com o fato de apresentarem ou não semelhanças de ordem grafo-fônico-fonológica entre si, ensejando, assim, efeitos de priming relacionado. Cabe frisar, no entanto, que os pares de palavras montados para o experimento não exibiam nenhum tipo de semelhanças semânticas. Em cada condição, foram utilizados 6 pares de palavras. Para este artigo, analisaram-se os dados de 7 dessas possibilidades de combinação entre as línguas, todas evidenciando priming grafo-fônico-fonológico relacionado. As combinações utilizadas evidenciam priming e alvo nas seguintes ordens de apresentação: português-português (P-P), francês-francês (F-F), inglês-inglês (I-I), português-francês (P-F), francês-português (F-P), português-inglês (P-I), inglês-português (I-P). Na figura abaixo (figura 3), apresenta-se uma listagem de todos os tipos de combinação que fizeram parte do experimento, porém, as combinações que serviram de análise para esta pesquisa são destacadas para serem mais bem visualizadas.

\begin{tabular}{|c|c|c|}
\hline Combinação das línguas & \multicolumn{2}{|c|}{ Condição } \\
\hline português-PORTUGUÊS & CPR & SPR \\
\hline inglês/INGLÊS & CPR & SPR \\
\hline francês/FRANCÊS & CPR & SPR \\
\hline português-INGLÊS & CPR & SPR \\
\hline inglês-PORTUGUÊS & CPR & SPR \\
\hline português-FRANCÊS & CPR & SPR \\
\hline francês-PORTUGUÊS & CPR & SPR \\
\hline francês-INGLÊS & CPR & SPR \\
\hline inglês- FRANCÊS & CPR & SPR \\
\hline
\end{tabular}

Fig. 3 - Possibilidades de combinação dos pares de palavras por língua e por condição de elaboração: com priming relacionado (CPR); sem priming relacionado (SPR). As flechas indicam as combinações analisadas neste artigo.

Ao realizar o experimento, os participantes recebiam dois estímulos (prime e alvo) em cada teste, tendo que decidir em qual língua estava a segunda palavra apresentada (palavra-alvo): português (L1), francês (L2) ou inglês (L3). A primeira palavra do par (o prime) sempre era apresentada em letras minúsculas, ficando na tela por 500 milissegundos, contrastando com a segunda palavra apresentada (palavra alvo), 
sempre em letras maiúsculas e permanecendo na tela até que os participantes pressionassem uma resposta. Os participantes foram instruídos a responder aos testes utilizando três teclas do teclado do computador: tecla "6", para palavras do português; "7", para palavras do francês; e "8", para palavras do inglês. O experimento foi precedido por uma sessão de prática, contendo 4 testes. No momento da testagem, os pares foram aleatorizados, apresentando, assim, ordens diferentes de aparecimento na tela do computador. Abaixo, a figura 2 apresenta o design do experimento.

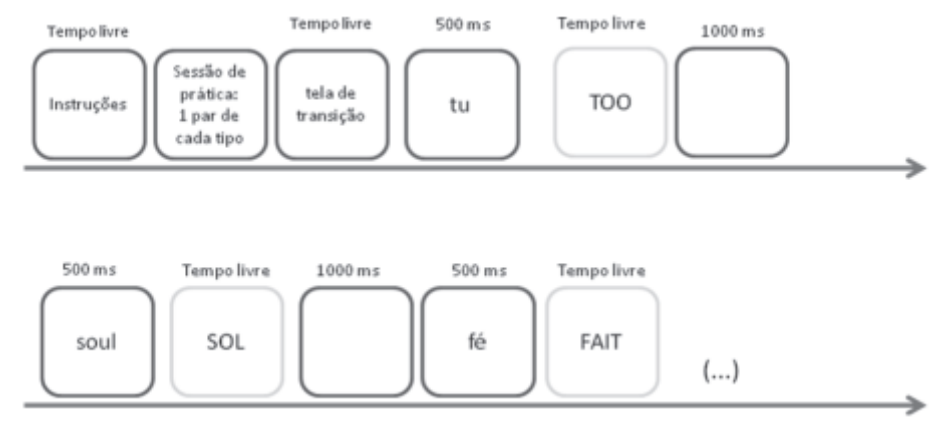

Fig. 4 - Design do experimento de decisão lexical trilíngue. O primeiro par apresentado (tu TOO) refere-se à combinação português-inglês com priming relacionado. O segundo par (soul - SOL) refere-se à combinação inglês-português com priming relacionado. O terceiro par exem-

plificado (fé - FAIT) refere-se à combinação português-francês com priming relacionado.

Para a construção e aplicação do experimento descrito, utilizou-se o software E-Prime, através do qual foi possível obter o tempo de reação dos participantes para responder a cada um dos pares testados. As palavras utilizadas nos testes foram extraídas de 3 diferentes corpora de línguas e tiveram suas frequências e número de sílabas controladas ${ }^{6}$.

Para a análise dos dados obtidos, os resultados de tempo de reação das 7 combinações aqui analisadas foram destacadas dos demais resultados obtidos para as demais combinações. Após este procedimento,

6 Todas as palavras utilizadas no experimento foram classificadas como de alta frequência e foram consultadas em corpora linguísticos (Ceten Folha, para o português, Lexique, para o francês, e Kucera e Francis, para o inglês). Todos os pares de palavras apresentados no experimento possuíam o mesmo número de sílabas, sendo que, dos 6 pares de palavras utilizados em cada combinação de línguas, 3 pares eram monossilábicos e 3 eram dissilábicos.

Organon, Porto Alegre, nº 51, julho-dezembro, 2011, p. 53-80 
os tempos de reação importantes para esta pesquisa passaram por tratamento estatístico. Foram obtidas as médias e os desvios-padrão para cada combinação analisada. Por fim, rodou-se o teste não-paramétrico Wilcoxon ( 2 related samples) para comparar os tempos de reação das combinações da seguinte forma: português-português (P-P) $\mathrm{x}$ francêsfrancês (F-F), português-português (P-P) $\mathrm{x}$ inglês-inglês (I-I), português-francês $(\mathrm{P}-\mathrm{F}) \mathrm{x}$ francês-português $(\mathrm{F}-\mathrm{P})$, português-inglês $(\mathrm{P}-\mathrm{I}) \mathrm{x}$ inglês-português (I-P).

A seguir, os resultados encontrados para as duas tarefas serão apresentados e discutidos.

\section{DESCRIÇÃO E ANÁLISE DOS RESULTADOS}

\section{Resultados do Stroop Test}

Com a aplicação desta tarefa, hipotetizou-se que haveria diferenças estatisticamente significativas entre o desempenho em funções executivas (controle inibitório e atenção) de crianças mono e multilíngues, na acurácia e no tempo de reação. O Teste Stroop foi realizado com o intuito de verificar se os multilíngues seriam mais rápidos e acurados do que os monolíngues na realização da tarefa. Foram utilizadas duas versões do teste, uma em português e outra em pomerano. O teste, na versão em português, foi realizado na sua íntegra pelos 40 participantes, 20 multilíngues e 20 monolíngues. Para comparar o desempenho entre os dois grupos, a tabela abaixo apresenta as médias para acurácia e tempo de reação para monolíngues e bi/multilíngues nas condições congruente e incongruente. Além disso, o resultado para o cálculo do efeito Stroop também é apresentado. Como análise complementar, foi aplicado um teste t para amostras independentes e os resultados são apresentados na sequência.

\begin{tabular}{cccccc}
\hline GRUPO & CONG (ms) & ACURÁCIA (\%) & INCONG (ms) & ACURÁCIA (\%) & EFEITO STROOP \\
& & & & & \\
\hline MONOLÍNGUES & 3250,35 & $97,75 \%$ & 2563,65 & $93,7 \%$ & 686,7 \\
& $(2222,1)$ & $(2,55)$ & $(1344,8)$ & $(8,5)$ & \\
\multirow{2}{*}{ MULTILÍNGUES } & 2636,10 & $94,0 \%$ & 2314,80 & $93,75 \%$ & 321,3 \\
& $(1344,9)$ & $(10,8)$ & $(986,2)$ & $(7,9)$ & \\
\hline
\end{tabular}

Tabela 1- Resultados do Stroop Test realizado em português por mono e multilíngues.

Organon, Porto Alegre, ํำ51, julho-dezembro, 2011, p. 53-80 
Como pode ser observado na tabela 1 , que apresenta as médias do Teste Stroop realizado em português, os monolíngues (falantes de PB) obtiveram uma média de 3250,35 ms na primeira condição (congruente), ao passo que os multilíngues obtiveram uma média de 2636,10 ms. Embora os multilíngues tenham sido mais rápidos no teste, a diferença entre os grupos não foi significativa $(t=1,058, p=0,297)$. Na segunda condição (incongruente), os monolíngues apresentaram uma média de 2563,65 ms, enquanto que os multilíngues levaram em média 2314,80 ms para executar a tarefa. Novamente, não foi verificada diferença estatística entre os grupos $(\mathrm{t}=0,695, p=0,491)$. Quanto à acurácia, na condição congruente, o grupo monolíngue obteve $97,75 \%$ de acertos na tarefa, ao passo que o grupo multilíngue atingiu uma média de $94 \%$ de acurácia no teste. Essa diferença de desempenho entre os grupos não foi significativa $(t=1,506, p=0,140)$. Na segunda condição (incongruente), não se observou diferença significativa entre os grupos $(\mathrm{t}=0,695, p=0,491)$. Em suma, no teste Stroop realizado em língua portuguesa, o tempo de reação dos monolíngues foi maior que o dos multilíngues em ambas as condições, mas não foram apuradas diferenças estatisticamente significativas entre os grupos. Na acurácia, a vantagem dos multilíngues sobre os monolíngues não resultou em diferença significativa em nenhuma das duas condições.

Contudo, quando o teste foi realizado na língua mãe dos multilíngues - o pomerano - os 20 participantes multilíngues tiveram um desempenho muito melhor, tanto no tempo de reação quanto em acurácia, chegando ao escore de $99,3 \%$ na acurácia, como pode ser observado na tabela 2. Todas as diferenças foram significativas, indicando que, na língua materna, os multilíngues obtiveram um desempenho significativamente melhor do que na L2.

\begin{tabular}{cccccc}
\hline GRUPO & CONG (ms) & ACURÁCIA (\%) & INCONG (ms) & ACURÁCIA (\%) & EFEITO STROOP \\
\hline MONOLÍNGUES & $2636,10^{*}$ & $94 \%^{*}$ & $2314,80^{*}$ & $93,75 \%^{*}$ & 321,3 \\
& $(1344,88)$ & $(10,83)$ & $(986,17)$ & $(7,9)$ & \\
MULTILÍNGUES & $1947,55^{*}$ & $98,75 \%^{*}$ & $1767,10^{*}$ & $99,3 \%^{*}$ & 180,45 \\
& $(620,64)$ & $(0,8)$ & $(679,2)$ & $(0,4)$ & \\
\hline
\end{tabular}

Tabela 2 - Resultados do teste Stroop realizado em PB e em pomerano por falantes de pomerano (L1).

Como se observa na tabela 2, que apresenta os resultados do teste Stroop em português e pomerano, realizado por falantes de pomera-

Organon, Porto Alegre, nº 51, julho-dezembro, 2011, p. 53-80 
no como L1, o tempo de reação é menor e a acurácia maior do que o mesmo teste realizado por tais participantes na sua L2, o português. A partir desses resultados, foi feita uma nova comparação entre os grupos, contrapondo os dados de ambos os grupos - mono e multilíngues, quando os testes foram realizados na língua mãe de cada um, conforme se pode observar na tabela 3 .

\begin{tabular}{cccccc}
\hline GRUPO & CONG (ms) & ACURÁCIA (\%) & INCONG (ms) & ACURÁCIA (\%) & EFEITO STROOP \\
\hline MONOLÍNGUES & $3250,35^{*}$ & $97,75 \%^{*}$ & $2563,65^{*}$ & $93,7 \%^{*}$ & 686,7 \\
& $(2222,1)$ & $(2,55)$ & $(1344,8)$ & $(8,5)$ & \\
\multirow{3}{*}{ MULTILÍNGUES } & $1947,55^{*}$ & $98,75 \%^{*}$ & $1767,10^{*}$ & $99,3 \%^{*}$ & 180,45 \\
& $(620,64)$ & $(0,8)$ & $(679,2)$ & $(0,4)$ & \\
\hline
\end{tabular}

Tabela 3 - Comparação de tempo de reação e acurácia entre monolíngues e multilíngues na sua

Por fim, foi feita uma análise estatística comparando os dados dos multilíngues no teste Stroop em pomerano com os dados dos monolíngues no teste Stroop em língua portuguesa. Na comparação entre os tempos de reação dos grupos na condição congruente houve diferença significativa entre os grupos ao redor de $1 \%$. Na segunda condição, incongruente, novamente foram encontradas diferenças estatisticamente significativas entre os grupos, tanto no tempo de reação quanto na acurácia.

A partir dos dados que foram descritos, pode-se presumir que ambas as línguas de um multilíngue podem estar ativadas quando ele tem de decidir qual das duas usar. Para tanto, o controle executivo é necessário, fazendo a sua parte no sistema de reorganização correspondente à língua que é requerida naquele momento, evitando que o sistema da outra língua interfira. Esse tipo de controle é feito constantemente por multilíngues na produção da linguagem. A inibição envolve a mudança da execução de uma resposta requerida em uma função do sistema em um nível mais motor.

Teste semelhante a este foi utilizado por Bialystok (2004) com crianças bilíngues para determinar se haveria vantagens no controle cognitivo em bilíngues. Na sua pesquisa, Bialystok encontrou resultados positivos quanto à rapidez em que os participantes bilíngues exerciam as tarefas e a acurácia, demonstrando que há melhor desempenho da 
memória de trabalho em bilíngues do que em monolíngues. Com o intuito de averiguar se o mesmo ocorreria com crianças bi e multilíngues, falantes de língua de imigração como o pomerano, este teste foi realizado. A hipótese de que as crianças bi e multilíngues apresentariam desempenho melhor no teste de Stroop foi parcialmente corroborada, pois houve diferença estatística apenas quando o teste de Stroop foi realizado na L1 dos participantes, como se verificou nesta seção.

A seguir, serão apresentados os resultados da tarefa de priming a que foram submetidos os participantes multilíngues adultos.

\section{Resultados da tarefa de priming}

$\mathrm{Na}$ tarefa de acesso lexical envolvendo as três línguas-alvo deste estudo, pares formados nas três línguas eram apresentados, devendo os participantes identificar em qual língua era apresentado o alvo em cada testagem.

Para iniciar as análises, começar-se-á com as condições-controle utilizadas no estudo: português-português (P-P), francês-francês (F-F) e inglês-inglês (I-I). A análise descritiva para essas condiçõescontrole revelou os seguintes resultados: os pares formados por prime e alvo em português foram os que apresentaram a menor média de tempo de reação (média: 1193,28, DP: 473,233), seguidos do inglês (média: 1226,33, DP: 533,163). A condição controle que apresentou o maior tempo de reação por parte dos participantes foi o francês (1256,00, DP: 452,628). Ao aplicar-se o teste Wilcoxon, encontraramse os seguintes resultados: para a comparação P-P x F-F, o teste aplicado não revelou um valor estatísticamente significativo $(\mathrm{p}=, 794)$. Para a comparação P-P x I-I, o teste Wilcoxon também não revelou um valor estatisticamente significativo $(\mathrm{p}=, 937)$. Por fim, compararam-se os valores de tempo de reação entre F-F e I-I, os quais também não demonstraram valor significativo $(\mathrm{p}=, 586)$. Passar-se-á, então, a analisar as condições interlinguísticas.

Analisando as médias e os desvios-padrão das combinações P-F e FP, verificou-se que a primeira combinação (P-F) evidenciou os maiores valores para ambas as medidas calculadas (média: 1116,77, DP: 250,021), ao contrário da segunda combinação, a F-P (média: 1016,33, DP: 206,213). O teste Wilcoxon, por sua vez, apresentou um valor significativo na com-

Organon, Porto Alegre, n 51, julho-dezembro, 2011, p. 53-80 
paração PF x FP $(p=, 038)$. Abaixo, a figura 5 é apresentada para que se tenha uma melhor visualização dos resultados.

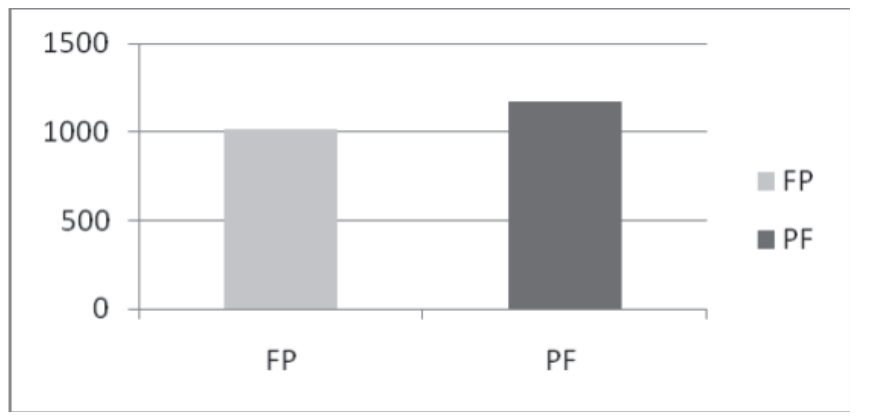

Fig.5 - Gráfico apresentando os valores das médias das combinações FP (azul) e PF (vermelho).

Levando-se em consideração os dados das combinações analisadas até o momento, pode-se dizer que os resultados apontam para um melhor desempenho em tempo de reação quando o alvo é apresentado na L1, o português. Contudo, quando o alvo é apresentado na L2, o francês, parece haver uma maior dificuldade para responder aos itens testados, já que há um aumento significativo no tempo de reação necessário para responder a esses tipos de pares.

As demais combinações de pares de palavras a serem analisadas trazem as seguintes combinações de priming e alvo: português-inglês (P-I) e inglês-português (I-P). Com base nas análises feitas, observa-se que a maior média e o maior desvio-padrão para os tempos de reação foram encontrados na combinação P-I (média: 1142,44, DP: 498,758), ao contrário do que foi encontrado para a combinação I-P (média: 1054,72, DP: 285,673). Porém, o teste Wilcoxon para a comparação das combinações não evidenciou um valor significativo estatisticamente $(p=, 500)$. De qualquer forma, embora o teste estatístico não tenha evidenciado uma diferença significativa entre os tempos de reação das combinações P-I e I-P, é importante referir que a combinação que apresentava a língua "não-materna" como alvo, ou seja, o inglês, L3 dos participantes, foi a que apresentou maior dificuldade para os sujeitos, já que a média de tempo de reação para as respostas foi superior em relação à combinação em que o alvo figurava em língua materna, o português. Assim, mesmo não havendo diferença significativa entre as combinações ana- 
lisadas, pode-se identificar um padrão nos resultados encontrados de maneira geral, uma vez que, nas 4 combinações analisadas, foram as duas combinações envolvendo línguas estrangeiras como alvo as que apresentaram tempos de reação mais altos para respostas. A figura 6 permite uma melhor visualização das diferenças entre as médias das duas combinações.

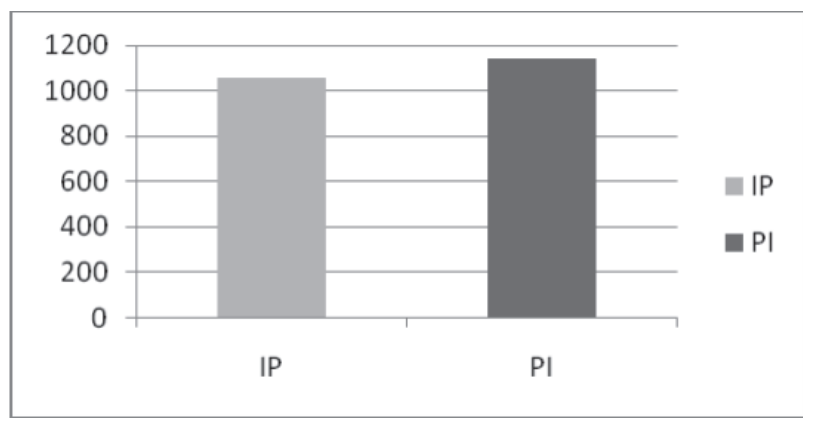

Fig. 6 - gráfico comparativo entre as médias das combinações I-P (azul) e P-I (vermelho).

Conforme foi possível observar, os resultados obtidos comprovam a hipótese anteriormente levantada nesta pesquisa, qual seja, a de os participantes teriam seu acesso lexical mais dificultado quando alvos fossem apresentados em francês, e não em inglês, considerando os primes testados sempre em português, L1 dos participantes. Nesse sentido, imagina-se que esse resultado esteja relacionado ao fato de os participantes terem comprovado uma maior proficiência na L2 do que na L3, indicando um maior estabelecimento do conhecimento grafofônico-fonológico da L2 dos participantes nos sistemas de memória. Nesse sentido, parece ter havido uma competição mais equilibrada desse conhecimento da L2 com o da correspondência grafo-fônicofonológica da língua materna, o português.

Por outro lado, quando o português figurava como alvo nos testes, os participantes tiveram menos dificuldade em responder prontamente, identificando e classificando as palavras-alvo pertencentes a essa língua sem tantas dificuldades.

De acordo com o modelo HipCort (MCCLELLAND et al., 1995), a aprendizagem e a criação de novas memórias se dá por meio das múl-

Organon, Porto Alegre, ํำ51, julho-dezembro, 2011, p. 53-80 
tiplas interações possíveis entre o sistema hipocampal e neocortical. Assim, as memórias começam a ser construídas via hipocampo e vão sendo vagarozamente relacionadas ao neocórtex, dependendo da intensidade com que forem submetidas a esses dois sistemas. Ao se escolher participantes trilíngues com alta proficiência em L2 (comprovada mediante realização de teste reconhecido internacionalmente), partiuse do princípio de que o conhecimento em francês como L2 desses participantes estava fortemente atrelado ao sistema neocortical. Por outro lado, ao se comprovar que os referidos participantes possuíam proficiência intermediária em inglês como L3 (comprovada mediante aplicação de teste de proficiência reconhecido internacionalmente), partiu-se do princípio de que o conhecimento desta língua deveria estar mais relacionado ao sistema de memória hipocampal. Aplicando-se, então, os achados do modelo HipCort aos resultados encontrados nesta pesquisa, pôde-se interpretá-los de forma a acreditar que os participantes apresentaram maior tempo de reação às respostas na combinação P-F, pela possibilidade de estar a sua L2 mais consolidada nos sistemas de memória, com um léxico de maior frequência de uso, competindo de forma mais equilibrada com os itens apresentados em português, língua materna dos participantes, na qual a proficiência é plena.

No caso do inglês, língua presumivelmente menos consolidada nos sistemas de memória, não se observaram resultados significativos nas comparações, embora tenha sido possível verificar um valor maior para tempo de reação a respostas na combinação P-I, em comparação com a combinação I-P.

Ainda pensando no funcionamento dos sistemas de memória, e tentando aplicar esse funcionamento ao modo como as diferentes línguas interagem por meio da cognição humana, pode-se pensar no fenômeno da transferência linguística não somente em relação às diferenças entre as línguas, mas também em relação às similaridades entre elas. No caso dos resultados explicitados neste artigo, são as semelhanças entre os corpos grafêmicos, ou seja, o fato de palavras do português e do francês apresentarem semelhanças grafêmicas ou fonético-fonológicas - além da alta proficiência em L2 e a falta de conteúdo semântico similar entre os pares de palavras testados - o que originou uma maior competição entre L1 e L2, fazendo com que os participantes demorassem mais para realizar suas escolhas em termos de classificação.

Organon, Porto Alegre, nํ51, julho-dezembro, 2011, p. 53-80 
Na próxima seção, serão feitas considerações finais a respeito dos dois experimentos tomados conjuntamente.

\section{CONSIDERAÇÕES FINAIS}

Em suma, este artigo traz evidências da dinamicidade de indivíduos multilíngues em tarefas verbais envolvendo controle inibitório e priming. Isso foi observado aqui para a questão do acesso lexical, já que corpos grafêmicos parecidos ativaram correspondências grafo-fônicofonológicas semelhantes, dificultando a decisão por uma das línguas, e evidenciando a impossibilidade de dissociação entre os padrões linguísticos. Nesse sentido, acredita-se que a relação dinâmica entre os padrões linguísticos fica mais clara, sendo que a proficiência linguística parece exercer um importante papel para que a interação entre línguas seja mais esperada. Assim, defende-se o papel da frequência do insumo como fator importante para que se note a transferência linguística gerada pela competição entre as línguas e defende-se também a visão de léxico como não seletivo para língua. Contudo, os resultados aqui expostos necessitam ser ampliados, com a coleta de número mais expressivo de participantes. Assim, conclusões mais sólidas poderão ser lançadas.

Quando se menciona a interação entre vários sistemas linguísticos, pode-se estender essa noção à interação entre sistemas cognitivos e às características típicas da Teoria dos Sistemas Dinâmicos, como o continuum e a interconectividade entre diferentes sistemas. Desse modo, quando se questiona por que os bi/multilíngues tiveram um melhor desempenho do que os monolíngues no teste Stroop, pode-se cogitar que o fator fundamental estaria ligado a essa característica do sistema cognitivo: a dinamicidade. Assim, o processamento executivo que envolve a atenção e a seleção, componentes do controle executivo central, beneficia-se da mesma condição de controle inibitório e atencional utilizada pelos multilíngues toda vez em que fazem o code switch numa interação bi/multilíngue. A vantagem do multilíngue reside no complexo processamento que é requerido pelo controle executivo. A interpretação dos dados nos leva a crer que o processamento executivo requerido para o gerenciamento no sistema linguístico de um multilíngue é evocado assim como no teste Stroop. Esses processamentos executivos não estão particionados somente no controle inibitório, mas sim de maneira mais geral, gerenciando

Organon, Porto Alegre, n 51, julho-dezembro, 2011, p. 53-80 
procedimentos complexos do processamento de controle. Nesse caso, a experiência de ser bi/multilíngue torna aspectos do processamento de controle de produção da língua relevantes na execução de tarefas cognitivas complexas em outros domínios, como o das funções executivas.

\section{ANEXOS}

\section{Palavras utilizadas no do teste de priming}

\begin{tabular}{|c|c|c|c|c|c|c|}
\hline P-F & F-P & P-I & I-P & P-P & F-F & I-I \\
\hline fé-fait & chat-chá & mas-mass & loose-luz & cem-sem & foi-fois & farther-father \\
\hline cor-corps & lait-lei & fim-fine & soul-sol & cara-caro & brume-brune & again-against \\
\hline mar-marre & mes-mês & meu-mail & so-som & ponto-ponte & bois-boit & two-too \\
\hline casar-casser & bateau-batom & feira-fairly & any-ano & casa-caso & enfant-enfin & basic-basis \\
\hline útil-outil & pourtant-portanto & leite-lady & ready-rede & mau-mão & cheveux-cheveaux & write-right \\
\hline santo-santé & depuis-depois & marca-market & county-conta & seu-céu & barque-barbe & hour-our \\
\hline
\end{tabular}

\section{BIBLIOGRAFIA}

BIALYSTOK, Ellen. Bilingualism in development: language, literacy and cognition. New York: Cambridge University Press, 2001.

BORINE, M. S. Consciência, emoção e cognição: o efeito do priming afetivo subliminar em tarefas de atenção. Ciências \& Cognição, v. 11, n. 24, p. 67-79, 2007.

BLANK, C. A transferência grafo-fônico-fonológica L2 (francês) - L3 (inglês): um estudo conexionista. Pelotas, RS. Dissertação de Mestrado. Universidade Católica de Pelotas - UCPel, 148p.

CENOZ, J. Research on multilingual acquisition. In: CENOZ, J.; JESSNER, U. (orgs.). English in Europe. The acquisition of a third language. Clevedon: Multilingual Matters, 2000.

ESLINGER P. J.; BIDDLE, K. R. Adolescent neuropsychological development after early right prefrontal cortex damage. Dev. Neuropsychol, v.18, n. 3, p. 297-329, 2000.

DE BOT, K. ; VERSPOOR, M.; LOWIE, W. Dynamical Systems Theory and Applied Linguistics: the ultimate 'so what'? International Journal of Applied Linguistics, v. 15, 116-118, 2004. 
DE BOT, K. The Multilingual Lexicon: Modeling Selection and Control. The International Journal of Multilingualism, v. 00, n. 00, 0115, 2004.

DIJKSTRA, T.; VAN HEUVEN, V. The architecture of the bilingual word recognition system. Bilingualism: Language and Cognition, v. 5, p. 175-197, 2002.

GAZZANIGA, Michael S., IVRY, R. B.; MANGUN, G. R. Cognitive neuroscience: The biology of the mind. New York: Norton \& Company, 2002. GREEN, D. W. Mental control of the bilingual lexico-semantic system. Bilingualism: Language and Cognition, v. 1, p. 67-81, 1998.

GREEN, D. W., CRINION, J., \& PRICE, C. Convergence, degeneracy and control. Language Learning, v. 56, n. 1, p. 99-125, 2006.

HAMDAN; BUENO, Orlando F. A. Relações entre controle executivo e memória episódica verbal no comprometimento cognitivo leve e na demência tipo Alzheimer. Estudos de Psicologia, v. 1, n. 10, p. 63-71, 2005.

HERNANDEZ, A. E. Language switching in the bilingual brain: what's next? Brain \& Language, n. 109, p. 133-140, 2009.

JARED, D.; KROLL, J. Do bilinguals activate phonological representations in one or both of their languages when naming words? Journal of Memory and Language, v. 44, p. 2-31, 2001.

KRISTENSEN, C. H.; ALMEIDA, R. M. M.; GOMES, W. B. Desenvolvimento histórico e fundamentos metodológicos em neuropsicologia. Psicologia: reflexão e crítica, v.14, n. 2, 2001.

KUCERA, H.; Francis, W. N. Computational analysis of present-day American English. Providence, RI: Brown UniversityPress, 1967.

LEZAK, M. D. Neuropsychological assessment. Oxford: University Press Inc., 1995.

MCCLELLAND, J. L; McNaughton, B. L; O'Reilly, R. C. Why there are complementary learning systems in the hippocampus and neocortex: insights from the successes and failures of connectionist models of learning and memory. Psychological Review,v. 102, n. 3, p. 419-457, 1995.

MOTA, M. B.; ZIMMER, M. C. Cognição e aprendizagem de L2: o que nos diz a pesquisa nos paradigmas simbólico e conexionista. Revista Brasileira de Lingüística Aplicada, v. 5, n. 2, p. 155-187, 2005.

Organon, Porto Alegre, nº 51, julho-dezembro, 2011, p. 53-80 
PINTO, L.; ZIMMER, M. C. O papel do bilinguismo na preservação dos processos executivos no envelhecimento. Caderno de Resumos do VI SENALE - Linguagens: metodologias de ensino e pesquisa. UCPel, Pelotas, p. 52-53, 2010.

VAN WIJNENDALE, Ilse; BRYSBAERT, M. Visual word recognition bilinguals: phonological priming from the second to the first language. Journal of experimental psychology: human perception and performance, v. 28, n. 3, p. 616-627, 2002.

ZIMMER, M. C.; ALVES, U. K.; SILVEIRA, R. A aprendizagem da L2 como processo cognitivo: a interação entre conhecimento explícito e implícito. Nonada, n. 9, p. 89-102, 2006.

ZIMMER, M. C.; FINGER, I.; SCHERER, L. Do bilingüismo ao multilingüismo: intersecções entre a psicolingüística e a neurolingüística. Revel. v. 6, n. 11, 2008. 